\title{
Strengthening Healthcare Facilities Through Water, Sanitation, and Hygiene (WASH) Improvements: A Pilot Evaluation of "WASH FiT" in Togo
}

Nicole Weber, Andrea L. Martinsen, Amidou Sani, Elom Kokou Eric Assigbley, Chedly Azzouz, Arabella Hayter, Komlan Ayite, Amivi Afefa Bibiane Baba, Kokou Mawulé Davi, and Rick Gelting

Water, sanitation, and hygiene (WASH) services in healthcare facilities are essential to ensure quality health care and to facilitate infection, prevention, and control practices. They are critical to responding to outbreaks and preventing healthcare-associated infections and, therefore, critical to global health security. Many healthcare facilities in low- and middle-income settings have limited WASH services. One tool to address this issue is the World Health Organization (WHO) and United Nations Children's Fund (UNICEF) Water and Sanitation for Health Facility Improvement Tool, or "WASH FIT." WASH FIT is a continuous improvement tool based on key WHO environmental health and infection, prevention, and control standards. While using WASH FIT, internal teams regularly perform self-assessments at their facilities, using up to 65 WASH indicators to develop and implement an improvement plan. The Ministry of Health and Social Protection (MSPS) in Togo, with support from WHO and the US Centers for Disease Control and Prevention (CDC), piloted this tool in 3 healthcare facilities. The pilot included facility assessments at 3 time points and in-depth interviews and document review 7 months after initiating WASH FIT. Facilities made improvements without significant external financial or material support. On average, pilot facilities improved from $18 \%$ of total indicators meeting standards at baseline to $44 \%$ after 7 months. Examples included improved drinking water supply, medical waste segregation, and increased soap at handwashing stations. Participants reported improvements in staff and patient satisfaction, hand hygiene, and occupational safety. Findings suggest that WASH FIT, coupled with training and supervision, may help facilities improve WASH services and practices, thus contributing to global health security. Based on these findings, the Togolese MSPS plans to scale up nationwide.

Nicole Weber, MPH, is an Oak Ridge Institute for Science and Education (ORISE) Fellow, Emergency Response and Recovery Branch, Center for Global Health, Division of Global Health Protection, Centers for Disease Control and Prevention, Atlanta, GA. Andrea L. Martinsen, MPH, and Rick Gelting, PhD, are with the Emergency Response and Recovery Branch, Center for Global Health, Division of Global Health Protection, Centers for Disease Control and Prevention, Atlanta. Amidou Sani, MSc; Elom Kokou Eric Assigbley, MSc; and Komlan Ayite are with the Direction de l'Hygiène et de l'Assainissement de Base (DHAB), Ministère de la Santé et la Protection Sociale (MSPS), Togo. Chedly Azzouz, MRes, is a consultant, Infection Prevention \& Control Global Unit, Service Delivery and Safety, HIS, World Health Organization, Geneva. Arabella Hayter, MSc, is a consultant, Water, Sanitation, Hygiene and Health Department, World Health Organization, Geneva. Amivi Afefa Bibiane Baba, MD, is with Direction des Établissements de Soins de de Réadaptation au Ministère de la Santé et de la Protection Sociale (MSPS), Togo. Kokou Mawulé Davi, $\mathrm{MD}, \mathrm{MPH}$, is with the World Health Organization, Togo. The findings and conclusions in this report are those of the authors and do not necessarily represent the official position of the Centers for Disease Control and Prevention. 
Keywords: Global health security, Healthcare facilities, Hygiene, Sanitation, Water, Infection control

Les services d'eau, d'assainissement, et d'hygiène (WASH) dans les établissements de santé sont essentiels pour assurer des soins de qualité et faciliter les pratiques de prévention et contrôle des infections. Ils sont essentiels pour répondre aux épidémies et prévenir les infections associées aux soins de santé, et donc à la sécurité sanitaire mondiale. De nombreux pays à revenu faible ou intermédiaire ont des services WASH limités dans les établissements de soins. Un outil récemment publié pour remédier cette situation est l'outil WASH FIT [Water and Sanitation for Health Facility Improvement Tool] de l'Organisation mondiale de la Santé (OMS) et le Fonds des Nations Unies (UNICEF) pour l'amélioration de l'eau et l'assainissement dans les formations sanitaires. WASH FIT est un outil d'amélioration continue basé sur les normes de l'OMS en matière de santé environnementale et de prévention et contrôle des infections. Lors de l'utilisation de WASH FIT, les équipes internes effectuent régulièrement des auto-évaluations dans leurs installations en utilisant jusqu'à 65 indicateurs pour élaborer et mettre en œuvre leur plan d'amélioration. Le ministère de la Santé et de la Protection Sociale (MSPS) du Togo, avec le soutien de l'OMS et les Centres pour le contrôle et la prévention des maladies (CDC), a fait un pilotage de cet outil dans 3 centres de santé. Ce pilotage comprenait 3 évaluations dans chaque formation sanitaire, des interviews approfondies, et une revue documentaire, 7 mois après l'initiation du WASH FIT. Les formations sanitaires ont réalisé des progrès, sans aide financière ou matérielle extérieure. En moyenne, les formations sanitaires sont passées de 18\% des indicateurs atteignant les standards au départ, à $44 \%$ après 7 mois. Les exemples incluent l'approvisionnement en eau potable, le tri des déchets médicaux, et le savon aux points de lavage des mains. Les participants ont signalé des améliorations dans la satisfaction du personnel et des patients, l'hygiène des mains, et la sécurité au travail. Les résultats indiquent que WASH FIT, associé à la formation et à la supervision, pourrait être un outil pour aider les formations sanitaires à améliorer les services et pratiques WASH, contribuant ainsi à la sécurité sanitaire mondiale. Sur la base de ces résultats, le MSPS prévoit une extension à l'échelle nationale.

Mots-clés: Sécurité sanitaire mondiale, Formation sanitaire, Hygiène, Assainissement, Eau, Contrôle de l'infection

A CCess to ADEQUate Water, sanitation, and hygiene (WASH) services in healthcare facilities is critical to providing quality care. WASH services support infection, prevention, and control practices to prevent and respond to outbreaks of infectious diseases. Lack of running water for handwashing, cleaning, and disinfection at healthcare facilities was a significant logistical challenge to contain the Ebola epidemic of West Africa in 2014-2016. ${ }^{1}$ In many low- and middle-income countries, healthcare facilities are ill equipped to ensure staff and patient safety and to respond to outbreaks. According to a recent report among 78 low- and middle-income countries, $50 \%$ of healthcare facilities lack piped water on premises and 33\% do not have improved sanitation. Additionally, 39\% do not have soap and water for handwashing, and 39\% lack proper medical waste management services. ${ }^{2}$ Levels of access are even lower in rural clinics in sub-Saharan Africa. ${ }^{3}$ Because WASH is critical for preventing, controlling, and responding to infectious disease outbreaks, WASH in healthcare facilities is a critical component for improving global health security.

Under the Global Health Security Agenda (GHSA), the US Centers for Disease Control and Prevention (CDC) have supported the World Health Organization (WHO) country office and the Ministry of Health and Social Protection (MSPS) in Togo to improve WASH in healthcare facilities. This included the development of the national infection, prevention, and control (IPC)/WASH action plan, ${ }^{4}$ a baseline assessment, training, and financing improvements in infrastructure and supplies in selected facilities in 15 priority districts of the total 40 health districts in Togo. Districts with an epidemic of cholera, meningitis, Lassa fever, or other communicable disease in the past year or with a vulnerable border to a neighboring country were prioritized. CDC technical assistance focused on WASH, while the WHO IPC Global Unit provided expertise in infection, prevention, and control. MSPS, with WHO and CDC support, conducted a baseline assessment of WASH and IPC in 364 healthcare facilities, using an evaluation tool adapted for Togo, in 15 priority districts in April 2017. The baseline assessment included a random selection of primary care facilities and a systematic selection of hospitals. Results indicated that among surveyed healthcare facilities, $80 \%$ had access to an improved water source on premises, $85 \%$ had improved sanitation facilities designated for patients, $69 \%$ had sanitation facilities for staff, $17 \%$ had handwashing stations for the public, and $31 \%$ had a functional incinerator. ${ }^{5}$ 
To further expand basic WASH services and improve infection, prevention, and control activities, the MSPS and WHO country office in Togo, with WHO Global IPC Unit and CDC support, launched a pilot of the WHO/UNICEF Water and Sanitation for Health Facility Improvement Tool, or "WASH FIT," in April 2017 in 3 of the healthcare facilities previously evaluated in the baseline assessment. Initially published in 2017, WASH FIT provides a risk-based, continuous improvement framework, including a set of tools for undertaking WASH/IPC and management-related improvements in healthcare facilities. ${ }^{6}$ It was developed based on the WHO essential environmental health standards in health care ${ }^{7}$ and the WHO guidelines on core components of infection, prevention, and control programs at the national and acute healthcare facility level. ${ }^{8}$ WASH FIT was developed through an iterative 2-year pilot process during which the training materials and the field guide were revised.

While WASH FIT has not been extensively evaluated, it was based on the risk assessment approach used in water safety plans. ${ }^{9}$ WASH FIT also supports other quality improvement efforts, as improvements resulting from WASH FIT can enhance infection, prevention, and control practices and patient, staff, and visitor safety. It is designed to be undertaken by a facility-based project team, ideally with community stakeholders as well. WASH FIT includes modifiable tools and guides for creating a team and recording meeting minutes, a facility-based assessment tool, sanitary inspection forms, a risk matrix, and improvement plan templates. WASH FIT is a framework and is intended to be adapted to each individual context.

The assessment tool is composed of 4 domains: (1) water, (2) sanitation, (3) hygiene, and (4) management of the facility. These broad domains include indicators on water quality, medical waste management, laundry, cleaning and disinfection, and wastewater. The hygiene and management domains include environmental health-based elements such as cleanliness, hand hygiene, vector control, and associated training. (See Table 1 for examples of essential indicators.) The WASH FIT team identifies gaps using the facility-based assessment tool. They score, analyze, and use these results to develop the WASH FIT improvement plan and to determine which indicators to address, based on level of risk and feasibility. As this is an iterative process, the facility-based team revisits the assessment tool at regular intervals to assess progress and to continue to make improvements. ${ }^{6}$

Seven months after the pilot launch, MSPS, with the support of CDC and WHO, evaluated this project. This evaluation aimed to document the process of WASH FIT, including key inputs and activities; to assess intermediate outcomes of the implementation; and to document challenges and lessons learned. Additionally, the evaluation aimed to determine the acceptability and feasibility of scaling up the use of WASH FIT. This article presents key outcomes achieved and barriers faced during the pilot implementation of WASH FIT in Togo. Furthermore, it provides recommendations to scale up the use of this tool.

\section{Methodology}

\section{Pilot Site Selection}

A 1-week training on infection, prevention, and control and WASH for healthcare staff from the 15 priority districts was conducted by MSPS and supported by CDC, WHO Togo, and the WHO Global IPC Unit in Kpalime, Togo. The key topics covered during the training, which included an introduction to WASH FIT, were: standard precautions, hand hygiene, medical waste management, personal protective equipment (PPE), water, sanitation and hygiene standards in healthcare facilities, cleaning and disinfection, and introduction to WASH FIT.

Following the training, 3 facilities were selected by MSPS to pilot WASH FIT. MSPS selected facilities close to the capital to enable easy and low-cost supervisory visits during this pilot period. All 3 structures were primary carelevel facilities and are described in Table 2. ${ }^{10}$

\section{WASH FIT Launch}

A joint team from MSPS and CDC visited the 3 pilot facilities in April 2017. The purpose of the launch was to introduce WASH FIT, to establish the facility-based WASH FIT team, and to conduct a detailed walk-through observation of the healthcare facility. This involved observing aspects of the facility, including the patient care areas, the water supply and storage infrastructure, sanitation facilities, wastewater and medical waste management systems, posted education materials, and some behaviors, such as medical waste sorting.

\section{Facility Assessments}

During the launch at the pilot facilities, the newly formed WASH FIT facility team and the MSPS/CDC team filled out the WASH FIT facility assessment tool as a baseline. The team drafted an improvement plan based on these results.

MSPS planned to conduct follow-up at midline after 3 months and at endline after 6 months; however, due to schedule conflicts and staff availability, they visited all pilot facilities after 5 months and 7 months. During these visits, they conducted the facility assessments again to evaluate progress against the improvement plan and compare indicators with baseline. MSPS was also able to provide any needed technical assistance at this time.

\section{Evaluation Methods}

This evaluation used a mixed-methods approach, which included in-depth interviews, descriptive analysis of the facility assessment data, and document review. The facility observations and quantitative assessment tool objectively identified improvements made in the facilities over the evaluation period. The qualitative in-depth interviews 
WEBER ET AL

Table 1. Examples of Essential Indicators and Related Scoring

\begin{tabular}{|c|c|c|c|c|}
\hline Domain & Indicator & $\begin{array}{c}\text { Does Not Meet } \\
\text { Standard (1) }\end{array}$ & $\begin{array}{l}\text { Partially Meets } \\
\text { Standard (2) }\end{array}$ & $\begin{array}{c}\text { Meets } \\
\text { Standard (3) }\end{array}$ \\
\hline \multirow[t]{2}{*}{ Water } & $\begin{array}{l}\text { 1.1 Water services available at } \\
\text { all times and of sufficient } \\
\text { quantity for all uses }\end{array}$ & $\begin{array}{l}\text { No improved water } \\
\text { source within } \\
\text { facility grounds, } \\
\text { or improved } \\
\text { supply in place } \\
\text { but not available }\end{array}$ & $\begin{array}{l}\text { Improved water supply } \\
\text { on premises (outside } \\
\text { of facility building) } \\
\text { and available }\end{array}$ & $\begin{array}{l}\text { Yes, improved water } \\
\text { supply within } \\
\text { facility and } \\
\text { available }\end{array}$ \\
\hline & $\begin{array}{l}\text { 1.10 Drinking water has } \\
\text { appropriate chlorine } \\
\text { residual }(0.2 \mathrm{mg} / \mathrm{l} \text { or } 0.5 \mathrm{mg} / \\
1 \text { in emergencies }) \text { or } 0 \text { e. colil } \\
100 \mathrm{ml} \text { and is not turbid }\end{array}$ & $\begin{array}{l}\text { Not treated/do not } \\
\text { know residual/do } \\
\text { not have capacity } \\
\text { to test residual/no } \\
\text { drinking water } \\
\text { available }\end{array}$ & $\begin{array}{l}\text { Chlorine residual exists, } \\
\text { but is less than } \\
0.2 \mathrm{mg} / \mathrm{l}\end{array}$ & Yes \\
\hline \multirow[t]{2}{*}{$\begin{array}{l}\text { Sanitation } \\
\text { and medical } \\
\text { waste }\end{array}$} & $\begin{array}{l}\text { 2.1 Number of available and } \\
\text { usable toilets or improved } \\
\text { latrines for patients }\end{array}$ & $\begin{array}{l}\text { Less than } 50 \% \text { of } \\
\text { required number } \\
\text { of latrines } \\
\text { available and } \\
\text { functioning }\end{array}$ & $\begin{array}{l}\text { Sufficient number } \\
\text { present but not all } \\
\text { functioning or } \\
\text { insufficient number }\end{array}$ & $\begin{array}{l}4 \text { or more } \\
\text { (outpatients) and } \\
1 \text { per } 20 \text { users } \\
\text { (inpatients) }\end{array}$ \\
\hline & $\begin{array}{l}\text { 2.12 Functional waste } \\
\text { collection containers for (1) } \\
\text { noninfectious (general) } \\
\text { waste, (2) infectious waste, } \\
\text { and (3) sharps waste in close } \\
\text { proximity to all waste } \\
\text { generation points }\end{array}$ & $\begin{array}{l}\text { No bins or separate } \\
\text { sharps disposal }\end{array}$ & $\begin{array}{l}\text { Separate bins present } \\
\text { but lids missing or } \\
\text { more than } 3 / 4 \text { full; } \\
\text { only } 2 \text { bins (instead } \\
\text { of } 3 \text { ); or at some but } \\
\text { not all waste } \\
\text { generation points }\end{array}$ & Yes \\
\hline \multirow[t]{2}{*}{$\begin{array}{l}\text { Hygiene } \\
\text { and cleaning } \\
\text { and disinfection }\end{array}$} & $\begin{array}{l}\text { 3.1 Functioning hand hygiene } \\
\text { stations are available at all } \\
\text { points of care }\end{array}$ & Not present & $\begin{array}{l}\text { Stations present, but no } \\
\text { water and/or soap or } \\
\text { alcohol-based } \\
\text { handrub solution }\end{array}$ & Yes \\
\hline & $\begin{array}{l}\text { 3.6 The exterior of the facility } \\
\text { is well fenced, kept generally } \\
\text { clean (free from solid waste, } \\
\text { stagnant water, no animal or } \\
\text { human feces in or around } \\
\text { the facility premises, etc) }\end{array}$ & Not kept clean at all & $\begin{array}{l}\text { Partly but } \\
\text { improvements could } \\
\text { be made; yes, } \\
\text { sometimes }\end{array}$ & Yes \\
\hline Management & $\begin{array}{l}\text { 4.2 An annual planned budget } \\
\text { for the facility is available } \\
\text { and includes funding for } \\
\text { WASH infrastructure, } \\
\text { services, personnel and the } \\
\text { continuous procurement of } \\
\text { WASH items (hand hygiene } \\
\text { products, minor supplies to } \\
\text { repair pipes, toilets, etc), } \\
\text { which is sufficient to meet } \\
\text { the needs of the facility. }\end{array}$ & No budget & $\begin{array}{l}\text { Yes, but budget is } \\
\text { insufficient }\end{array}$ & Yes \\
\hline
\end{tabular}

further identified perceived improvements, barriers to implementation, and recommendations.

The evaluation team conducted in-depth interviews solely at endline, between November 7 and 14, 2017, and compared facility assessment data collected at baseline, midline, and endline over the period of April to November 2017.

\section{Interviews}

Interviews were conducted using semi-structured interview guides. At each facility, WASH FIT team members with varying roles (eg, director, midwife, cleaner, hygiene technician) were included to gain different perspectives. The evaluation team interviewed staff based on their participation in WASH FIT during the pilot and their availability 


\section{A PILOT EVALUATION OF "WASH FIT" IN TOGO}

Table 2. Selected Characteristics of the Healthcare Facilities Included in the Pilot Project

\begin{tabular}{|c|c|c|c|c|}
\hline \multicolumn{2}{|l|}{ Items } & HCF 1 & HCF 2 & HCF 3 \\
\hline \multicolumn{2}{|l|}{ Type } & $\begin{array}{l}\text { Centre medico-social } \\
\text { (CMS)/ Medical Care } \\
\text { Structure }\end{array}$ & $\begin{array}{l}\text { Centre medico-social } \\
\text { (CMS)/ Medical Care } \\
\text { Structure }\end{array}$ & $\begin{array}{l}\text { Unite de soins } \\
\text { peripherique (USP) / } \\
\text { Peripheral Care Unit }\end{array}$ \\
\hline \multicolumn{2}{|l|}{ Services offered } & $\begin{array}{l}\text { Curative care unit, } \\
\text { maternity ward, drug } \\
\text { depot, laboratory, } \\
\text { patient observation unit, } \\
\text { family planning, and } \\
\text { promotion of basic } \\
\text { hygiene and sanitation }\end{array}$ & $\begin{array}{l}\text { Curative care unit, } \\
\text { maternity ward, drug } \\
\text { depot, laboratory, } \\
\text { patient observation unit, } \\
\text { family planning, and } \\
\text { promotion of basic } \\
\text { hygiene and sanitation }\end{array}$ & $\begin{array}{l}\text { Curative care, maternal } \\
\text { and infant care, } \\
\text { family planning, } \\
\text { drug depot, } \\
\text { laboratory }\end{array}$ \\
\hline \multicolumn{2}{|c|}{$\begin{array}{l}\text { Estimated population served } \\
\text { by facility }\end{array}$} & 19,338 & 57,858 & 23,599 \\
\hline \multicolumn{2}{|l|}{ Location } & rural & urban & rural \\
\hline \multicolumn{2}{|c|}{ Number of beds } & 14 & 15 & 6 \\
\hline \multicolumn{2}{|l|}{ Incinerator } & No & Yes & Yes \\
\hline \multicolumn{2}{|l|}{ Water source } & Tube well & $\begin{array}{l}\text { Piped municipal water } \\
\text { supply }\end{array}$ & $\begin{array}{l}\text { Piped municipal water } \\
\text { supply }\end{array}$ \\
\hline \multirow{9}{*}{$\begin{array}{l}\text { Personnel } \\
\text { description }\end{array}$} & Physician & 0 & 1 & 0 \\
\hline & Medical assistant & 1 & 4 & 0 \\
\hline & Nurse & 2 & 3 & 2 \\
\hline & Midwife & 5 & 10 & 1 \\
\hline & Hygiene technician & 1 & 1 & 0 \\
\hline & Laboratory technician & 2 & 2 & 0 \\
\hline & Cleaner $^{\mathrm{a}}$ & 0 & 3 & 0 \\
\hline & Staff & 3 & 11 & 1 \\
\hline & Total & 14 & 35 & 4 \\
\hline
\end{tabular}

${ }^{a}$ The personnel responsible for cleaning in HCF 1 and HCF 2 were recruited primarily for other tasks and therefore are classified as midwife and staff.

for an interview. National-level MSPS staff were also interviewed. Participants completed a written consent form prior to the interview. All interviews were completed by staff from CDC, WHO, and MSPS. Twelve interviews were conducted in French and 1 in a local language with consecutive interpretation by MSPS.

All interviews were audio recorded, transcribed verbatim, de-identified, and analyzed using content analysis. ${ }^{11}$ All data were analyzed in French, including the interview originally conducted in a local language, which was transcribed in French. CDC analysts used some predetermined codes based on the interview guides and added emergent codes during the coding process. Two analysts independently coded 7 randomly selected transcripts in Microsoft Word. Discrepancies were discussed to determine final coding, and the codebook was revised as needed. One analyst coded the remaining transcripts and entered the coded data into Microsoft Excel. Microsoft Word and Excel were used because of the small data set.

\section{Facility Assessments and Document Review}

Data from the facility assessments completed at baseline, midline, and endline were entered into Excel for each healthcare facility. According to WASH FIT guidelines, indicators were classified using a 3-point scoring system, which consists of meeting standards (3 points), partially meeting standards (2 points), or not meeting standards (1 point). All indicators and requirements for meeting standards were defined in the WASH FIT guide. ${ }^{6}$ Where there were multiple points of care, all points of care needed to meet the standard to receive 3 points. The WASH FIT guide defined points of care as "where 3 elements come together: the patient; the healthcare workers; and care or treatment involving contact with the patient or their surroundings. This may include consultation rooms, operating rooms, delivery rooms, and laboratories." ${ }^{\prime 6}$ If some, but not all points of care met the standard, this was marked as partially or not meeting the standard, depending on the indicator. All indicators were equally weighted. All analyses were done in Microsoft Excel to document change over 
time. The evaluation team also reviewed team minutes and improvement plans at each facility.

\section{Data Triangulation}

CDC analysts compared data collected from in-depth interviews with data collected from facility observations, assessments, and document review. This allowed a comparison of self-reported information through the interviews and facility assessments with observations.

The protocol and the interview guides were reviewed by the CDC Institutional Review Board and determined to be a nonresearch public health activity under the project determination number 2017-354.

\section{RESUlts}

\section{Key Findings}

Results herein focus on achieved outcomes and barriers at the pilot facilities, although the WASH FIT process and inputs were also assessed. Findings include facility improvements (assessed via the facility assessment tool and in-depth interviews), patient and staff experiences using the WASH FIT tool, changes in healthcare facility policies and finances, and challenges and barriers during implementation.

\section{Facility Improvements}

As shown in Figure 1, facilities documented changes in all 4 domains of WASH FIT included in the facility assessment tool over the evaluation period. The number of indicators evaluated ranged from 59 to 61 at each facility, with a possible maximum score of 65 . Table 3 lists the number of indicators that were evaluated at each facility per domain.

On average, pilot facilities increased the percentage of indicators meeting standards from $18 \%$ at baseline to $44 \%$ at endline. Each team implemented interventions targeting drinking water supply, medical waste management, facility cleanliness, and availability of soap at handwashing stations. In all pilot facilities, the water domain had the highest percentage of indicators meeting standards, with an average of $48.7 \%$ at baseline (range: 30.8 to 69.2 ) and $71.8 \%$ (range: $61.5 \%$ to $84.6 \%$ ) at endline. All 3 facilities increased water storage capacity and improved drinking water quality. The area with the lowest percentage of indicators meeting standards was medical waste management, with an average of $6.5 \%$ at baseline (range: 0.0 to 11.1 ) and $22.6 \%$ at endline (18.2 to 30.0$)$. Other indicators that improved included increased visible cleanliness of facilities, separating toilets by gender, improved lighting, and medical waste sorting. While most indicators either increased or remained the same, indicators for management, hygiene, and sanitation at healthcare facility 1 increased from baseline to midline and then decreased at endline.

\section{Results from Interviews and Observations}

This section presents the qualitative results of the final evaluation. In-depth interviews participants included facility directors, healthcare providers, hygiene and sanitation technicians, a cleaner, and national level staff. This included 6 males and 7 females and 11 facility-level staff and 2 national-level staff (Table 4). Most participants (12) were French-speaking, and 1 spoke only a local language. Interviews averaged 50 minutes (range 15-84 minutes).

In-depth interviews and observations noted progress in all facilities; however, at least 1 interviewee at each facility stated that additional improvements were needed. Table 5 provides an overview of themes and key quotes from interviews, describing facility improvements and improvements in operations and management across the 4 domains.

As described in Table 6, most participants felt that using WASH FIT resulted in an improved understanding among healthcare facility workers of key WASH and infection, prevention, and control behaviors and the risks associated with poor practices or services. One healthcare facility director stated that this perception of risk can motivate staff to undertake WASH FIT-related activities. A national-level interviewee suggested that this may translate into staff empowerment and refusal to work if minimal safety conditions remained unmet. Some participants at the facilities and both national-level participants cited that staffs WASH/IPC behaviors had improved. The evaluators noted behavior changes in both improved medical waste segregation and cleanliness during the facility observation at endline. National-level supervision was cited by participants as being a motivating factor for making changes as well for the technical advice that they received during the 3 facility visits, thus improving knowledge and awareness.

Participants across the 3 pilot facilities stated that the WASH FIT process improved occupational safety (Table 6). A midwife stated that the process helped staff to protect themselves against infections, and 1 nurse reported providing better care when she was healthy. One cleaner described the consequences of occupational hazards encountered prior to WASH FIT: "This infection made invalids of some colleagues. They were infected, and they can no longer work. They are at home."

In 2 facilities, some participants reported improvements in staff satisfaction. In 1 facility, this stemmed from making potable drinking water available on site to staff. Some participants highlighted improvements in patient safety or reported having received positive feedback from patients. Feedback was mainly concentrated on improved cleanliness, the presence of mosquito nets, and improved bed spacing.

At the time of the evaluation, we noted several financial or policy changes. Staff from all 3 facilities reported planning to integrate WASH FIT into their 2018 budgets. Both national-level staff reported interest in including WASH FIT in their national plans, as they felt that 


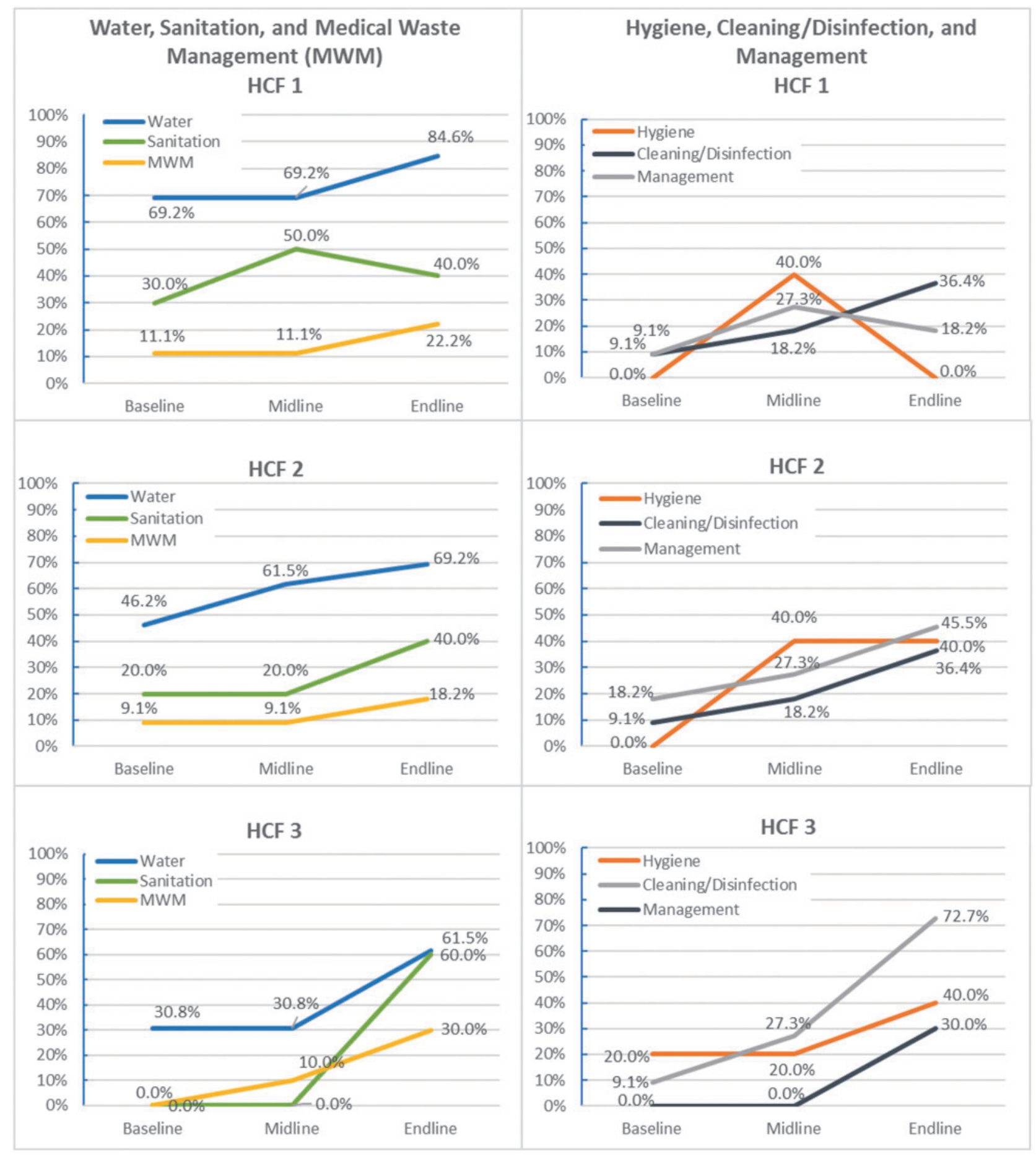

Figure 1. Percentage of indicators meeting WASH FIT standards over time per domain* and facility

Table 3. Number of Indicators Evaluated per Domain at Each Facility

\begin{tabular}{|l|c|c|c|c|c|c|c|}
\hline & Total & Water & Sanitation & Medical Waste & Hygiene & Cleaning/ Disinfection & Management \\
\hline HCF 1 & 59 & 13 & 10 & 9 & 5 & 11 & 11 \\
\hline HCF 2 & 61 & 13 & 10 & 11 & 5 & 11 & 11 \\
\hline HCF 3 & 60 & 13 & 10 & 11 & 5 & 11 & 10 \\
\hline
\end{tabular}


Table 4. Profile of In-depth Interviewees

\begin{tabular}{|l|c|c|c|c|c|c|c|}
\hline & Maternity $^{\mathrm{a}}$ & Director & Medical Provider & Hygiene Sanitation Technician $^{\mathrm{b}}$ & Cleaners & National Level $^{\text {Total }}$ \\
\hline Male & 0 & 0 & 1 & 3 & 0 & 2 & 6 \\
\hline Female & 3 & 2 & 1 & 0 & 1 & 0 & 7 \\
\hline Total & 3 & 2 & 2 & 3 & 1 & 2 & 13 \\
\hline
\end{tabular}

${ }^{a}$ This includes 1 maternity director, who was acting as interim director for 1 week.

${ }^{\mathrm{b}}$ This includes a pharmacist whose job description also includes hygiene.

the pilot facilities have made greater improvements in WASH than facilities not using WASH FIT. Additionally, national-level staff engaged additional donors to support further WASH FIT training and scale-up.

\section{Perceived Barriers and Challenges}

Participants across the 3 pilot facilities identified financial and material constraints and the hierarchical culture of the organization as challenges to implementing WASH FIT. Additionally, some participants identified the workload and time as barriers. Table 7 provides a summary of key findings and representative quotes.

\section{Financial and Material Resources}

Across all facilities, funding was a barrier to implementing some parts of the improvement plan. This included financing for infrastructure and procuring materials such as hand hygiene promotional posters, chlorine, soap, colored bags for waste segregation, and personal protective equipment. While the 3 pilot facilities were within the area targeted by the broader IPC/WASH project, they had been trained but had not yet received financial or material support from the project at the time of the endline. This barrier limited the uptake of some key prevention measures. For example, in 1 healthcare facility, costs prohibited the installation of a sink in the delivery room. At another, the visitors' toilets were repaired and the facility put into a pay per use policy to cover toilet paper and cleaner costs. This cost recovery strategy resulted in complaints from visitors. All facilities had at least 1 interviewee who requested donor support for additional WASH FIT improvements. In addition, since WASH FIT was launched mid-year, activities were not included in the 2017 budget. However, all 3 facilities planned to include WASH improvements in their 2018 action plan and budget.

\section{Hierarchical Culture of the Organization}

Participants across the 3 pilot facilities described the hierarchical culture and centralized decision making of their organization as barriers to WASH FIT implementation. Some decisions were made by staff without direct knowledge or experience of the impacts of those decisions. For example, accountants played a key role in resource allocation; however, they did not typically have direct knowledge or receive sensitization regarding the importance IPC/ WASH. Participants perceived that accountants need more training and engagement to understand the need to allocate additional funds and the added benefit of using WASH FIT. This was especially needed because WASH investments do not result in immediate cost recovery. As stated by a hygiene technician:

We often say to invest in activities with return [on investments] that make money. Since WASH FIT does not make

Table 5. Key Findings and Quotes from Outcomes: Facility Improvements

\begin{tabular}{|l|l|l|}
\hline Domain & \multicolumn{1}{|c|}{ Key Finding } & \multicolumn{1}{c|}{ Key Quote } \\
\hline Domain 1: Water & Improved drinking water & $\begin{array}{c}\text { When they ask for something to drink all the time, it is good because } \\
\text { there is water. (Nurse, HCF 3) }\end{array}$ \\
\hline $\begin{array}{c}\text { Domain 2: Sanitation and } \\
\text { medical waste } \\
\text { management }\end{array}$ & $\begin{array}{c}\text { Improved sanitation (toilets } \\
\text { and wastewater) }\end{array}$ & $\begin{array}{c}\text { Before the [toilet block] structure was damaged, and the caregivers } \\
\text { went to the bathroom where they wanted to. It was not our } \\
\text { problem. Now, we fixed it ... we hired a woman to clean so that it } \\
\text { is clean every day. (Director, HCF 2) }\end{array}$ \\
\hline $\begin{array}{c}\text { Domain 3: Hygiene and } \\
\text { cleaning/disinfection }\end{array}$ & Improved hand hygiene & $\begin{array}{c}\text { We have new habits with WASH FIT, such as hand hygiene. There is } \\
\text { definitely a change with hand hygiene. (Director, HCF 3) }\end{array}$ \\
\cline { 2 - 3 } & Improved cleanliness & $\begin{array}{c}\text { The center is cleaner, pleasant to visit. The rooms are clean. (Hygiene } \\
\text { Technician, HCF 2) }\end{array}$ \\
\hline $\begin{array}{c}\text { Domain 4: Management } \\
\text { f. WASH FIT is a good thing to help us change our daily habits. } \\
\text { (Nurse, HCF 3) }\end{array}$ \\
\hline
\end{tabular}




\section{A PILOT EVALUATION OF "WASH FIT" IN TOGO}

Table 6. Key Findings and Quotes on Staff and Patient Experience

\begin{tabular}{|c|c|c|}
\hline Theme & Key Finding & Key Quote \\
\hline \multirow[t]{3}{*}{ Staff experience } & Increased awareness & $\begin{array}{l}\text { I look more after hygiene, especially of the material, of our rooms and our materials. } \\
\text { [...] The best part was that it [WASH FIT] helped us change a lot, to understand } \\
\text { what is hygiene. (Midwife, HCF 1) }\end{array}$ \\
\hline & Staff protection & $\begin{array}{l}\text { It helps the staff to be healthy, because we, too, we drink the water. It's not only the } \\
\text { patients. If we don't sort the waste, if we put syringes in a trash can somewhere. } \\
\text { When we take out the trash, we can find a syringe, we can get stuck, that's a } \\
\text { problem. When we sort [waste], we don't mix the sharps with the things with blood, } \\
\text { so it's good. (Hygiene Technician, HCF 1) }\end{array}$ \\
\hline & Staff satisfaction & $\begin{array}{l}\text { Before that, we didn't have water to drink. Someone would go out to pay for drinking } \\
\text { water. But now it is good. We are really proud of that. (Midwife, HCF 2) }\end{array}$ \\
\hline \multirow[t]{2}{*}{$\begin{array}{l}\text { Patient } \\
\text { experience }\end{array}$} & Patient protection & $\begin{array}{l}\text { Before, we infected our women, we infected our women because we did not practice } \\
\text { (hygiene) ... but now we practice more than before ... we contaminated our women } \\
\text { without knowing. (Midwife, HCF 3) }\end{array}$ \\
\hline & Patient satisfaction & They [patients] talk of the cleanliness, that your center is clean. (Midwife, HCF 1) \\
\hline
\end{tabular}

money directly, we do not see the need to invest in it right away.... I think there are two ways to recover this money.... It is not necessarily getting back the money, but we can get it back via health.

In addition, the district-level leadership was not well briefed about the WASH FIT process and hence were reported as not facilitating some WASH FIT activities.

\section{Workload and Behaviors}

Some participants noted limited personnel, time, and an increased workload due to WASH FIT activities. Across all facilities, some participants mentioned time to perform WASH FIT activities as a barrier. This was related to an increased workload, staff turnover, or inadequate number of staff to perform the additional activities required to meet the WASH FIT standards and to implement the improvement plan. Some participants reported that the WASH FIT assessment tool was too long or time consuming. One hygiene technician stated: "There is not enough time, not enough time, because we have many activities that we do outside of WASH FIT.” Staff at 2 facilities also underlined poor behaviors and habits as a barrier to WASH FIT implementation. As described by 1 nurse, sometimes staff are in a hurry and return to their old habits.

\section{Discussion}

Increased access to WASH services in healthcare facilities is needed in low- and middle-income countries in order to ensure staff and patient safety, to improve quality of care, and to strengthen global health security. As highlighted by the low coverage among low- and middle-income countries, providing WASH services is not always prioritized in healthcare facilities, despite these services being critical to fight healthcare-associated infections and antimicrobial resistance. The use of WASH FIT may contribute to the GHSA action packages, including the prevention of antimicrobial resistance and workforce development. By raising awareness of WASH and infection, prevention, and control and supporting facility-led incremental improvements,

Table 7. Key findings and Quotes on Barriers during implementation

\begin{tabular}{|l|l|}
\hline Key Finding & \multicolumn{1}{c|}{ Key Quote } \\
\hline Financial and material constraints & It's the cost, we haven't done these activities because of the costs. (Director, HCF 3) \\
\hline Hierarchical organization & $\begin{array}{r}\text { If the nurse [says] I want to do this, the DPS [the prefectural directorate of health]is going } \\
\text { to say no. If the DPS does not understand, they are going to say no. Therefore, we need } \\
\text { to strengthen them so that they are able to help, so that there is sustainability. (National } \\
\text { level interview) }\end{array}$ \\
\hline $\begin{array}{l}\text { Workload and behaviors } \\
\text { the beginning, the cleaner complained that her workload had increased. (Director, } \\
\text { HeF 2) } \\
\text { We have put 3 trashcans, but sometimes you can go and it is true that the sharps, they } \\
\text { put in the sharps box. But, the other 2, sometimes they mix it and you need to talk to } \\
\text { them again. So maybe it's the behavior that is a little difficult. (Director, HCF 2) }\end{array}$ \\
\hline
\end{tabular}


WASH FIT may help to increase capacity to prevent healthcare-associated infections and disease transmission during public health emergencies. This in turn improves facilities' preparedness to address challenges such as those experienced during the 2014-16 Ebola outbreak and subsequent Ebola outbreaks in West Africa.

The evaluation demonstrated that targeted facilities, when provided with training and supervisory visits, were able to make visible and measurable improvements in WASH/IPC services. Using WASH FIT, facilities prioritized specific actions based on risk and feasibility and made incremental improvements in services without external funding. Levels of achievement varied among the 3 pilot facilities and among domains; however, these differences may have been due to the size of the facility, leadership, staff commitment to making and sustaining improvements, or availability of funds. Additionally, each facility determined its own priorities for improvements and prioritized some domains over others. Several studies also suggest that improvements in practices decline over time after an intervention, and this may explain the decline from midline to endline at 1 healthcare facility in hygiene, management, and sanitation. ${ }^{12,13}$ Determining the specific levels of influence these various factors had on differing results and on sustaining changes among healthcare facilities and domains was not possible with the data collected in this pilot evaluation of a small number of facilities.

Some respondents reported improvements in occupational safety and in staff and patient satisfaction, potentially as a result of the improvements in WASH. However, previous studies documented a number of factors beyond the scope of WASH FIT that contribute to staff satisfaction (eg, job security, professional advancement, support networks, financial incentives) and to patient satisfaction (eg, medical care provided, interpersonal relations). ${ }^{14,15}$ Therefore, while WASH FIT may address some components, its effect may be limited on overall satisfaction levels.

Political commitment and engagement at both the national and district levels are necessary to implement WASH FIT successfully. Pilot facility staff reported that supervisory visits from national-level MSPS, in addition to verbal encouragement, were beneficial. During the pilot, there was limited involvement at the district level in WASH FIT. This may have been due to staff turnover and inadequate engagement and training of district staff at the start-up of the pilot.

As observed in other studies, participants in this evaluation cited budget, time, and hierarchical culture as barriers. In many settings, nonmedical professionals, such as accountants in the case of Togo, play a role in resource allocation decisions. ${ }^{16} \mathrm{~A}$ lack of engagement at the district level and with key financial decision makers was a barrier to making and sustaining WASH improvements in this pilot. Results also indicate that the effective implementation of WASH FIT improvement plans may require more staff time and personnel.

\section{Limitations}

The WASH FIT assessment tool weights all indicators and domains equally. Some indicators, such as water supply or sanitation facilities, may have more influence on facility practices and thus may need to be weighted more. For example, facilities need a regular water supply to achieve other key indicators, such as ensuring handwashing and facility cleanliness.

This evaluation was conducted 7 months after initiation of the WASH FIT process and was composed of a small pilot of 3 facilities that were located near the capital, had running water, and had sanitary facilities. The selection of sites was not random and not representative of all healthcare facilities in Togo. The presence of national leadership and external evaluators may have influenced the participants' responses and produced some social desirability in participants' reports of their experiences with WASH FIT. We intended to interview personnel at the district level in addition to the national level; however, this was not possible due to staff turnover and availability.

\section{Conclusions and Recommendations}

This evaluation generally showed WASH and related management improvements across the 3 pilot facilities over the evaluated period of the WASH FIT pilot. Additionally, there were perceived improvements in occupational safety, staff awareness of IPC/WASH, and patient and staff satisfaction. These results supported the decision to scale-up to additional healthcare facilities in Togo, which MSPS has begun.

WASH FIT provided the pilot facilities with tools to identify gaps at their facility in WASH services, to set clear benchmarks on how to improve indicators, to assess risks and priorities, and to develop an improvement plan that was feasible to implement. In the case of the pilot in Togo, all 3 pilot facilities made incremental improvements without large investments. Small financial and material inputs at the national level, limited to training and healthcare facility supervisory visits from national-level MSPS staff, were used during the pilot.

Costs at the facility level depended on the type of improvements made. While the use of WASH FIT can help facilities make quick wins, more resources would be needed for more costly infrastructure improvements in order to scale up. For example, some improvements, such as lighting in latrines, were much more feasible for facilities to meet, than other improvements, such as installation or repair of water supply infrastructure or medical waste incinerators. In addition, with adequate staffing and engagement of all key stakeholders, WASH FIT may be one approach and framework that countries could adapt to fit their specific context.

Without WASH services and practices, effective infection, prevention, and control is not possible, and without adequate infection, prevention, and control practices, 
healthcare facilities cannot ensure staff and patient safety. As demonstrated in this evaluation, WASH FIT can be a useful tool for improving WASH conditions in healthcare facilities and consequently contribute to global health security.

\section{Recommendations for Scale-Up}

During scale-up of WASH FIT in Togo, as with other global health security-related interventions, it is critical to assess the effectiveness of the approach and to plan to address the barriers identified during the pilot. While all facilities included in this evaluation had WASH FIT teams in place, more regular participation of all invested personnel could enhance staff buy-in. It is important to ensure that leaders in the facility understand the importance of staff participation and encourage additional staff to become involved. Prioritizing and including WASH and IPC activities in the annual budget, as planned, and in job descriptions is important to overcome this barrier. In addition, both medical and nonmedical personnel should be engaged in the design and implementation of WASH and IPC programs.

More engagement with other key government and community stakeholders may also aid the WASH FIT process. This includes coordinating with other ministries on ensuring adequate water supply, water quality monitoring, and infrastructure design according to national standards. One way to ensure sustained use of WASH FIT may be to include it in the national standards as a method to implement healthcare facility standards, such is the case in Cambodia and Madagascar. ${ }^{17,18}$

As national-level supervisors were a motivating factor in this pilot, it is recommended to conduct supervision at all facilities during scale-up. To ensure coverage at all facilities, district-level staff should be engaged in supervision.

\section{Recommendations for Future Evaluations}

Future evaluations in additional facilities could be strengthened by including patient exit surveys, staff surveys, and structured observations in facilities to evaluate key behaviors, review of budget expenditures, and a cost-effectiveness component. Annual assessments are necessary to determine the long-term effects and sustainability of using WASH FIT. Prioritization of WASH and IPC improvements may displace funds from other key facility activities; thus, this should be considered in future evaluations, particularly after longer implementation periods. For future evaluations, a validation process for weighting the indicators would be important. Research shows that quality improvement efforts, such as WASH FIT, have mixed effects and success rates depending on factors such as context, leadership, skills, organizational resources, and data availability. ${ }^{19}$ Therefore, the evidence base would benefit from additional evaluations of WASH FIT in diverse contexts to guide interventions in other settings.

\section{REFERENCES}

1. Cooper C, Fisher D, Gupta N, MaCauley R, Pessoa-Silva CL. Infection prevention and control of the Ebola outbreak in Liberia, 2014-2015: key challenges and successes. BMC Med 2016;14:2.

2. Cronk R, Bartram J. (2018). Environmental conditions in health care facilities in low- and middle-income countries: coverage and inequalities. Int J Hyg Environ Health 2018; 221(3):409-422.

3. WHO/UNICEF. Water, Sanitation and Hygiene in Health Care Facilities: Status in Low-and Middle-Income Countries and the Way Forward. Geneva: World Health Organization (WHO); United Nations Children's Fund (UNICEF); 2017. http://apps.who.int/iris/bitstream/handle/10665/154 588/9789241508476_eng.pdf;jsessionid=D1B71082C8CD9 515FD973A02068839B9? sequence=1. Accessed September 6, 2018.

4. Ministre de la santé et de la protection sociale, Direction de l'hygiène et de l'assainissement de base, Division de l'assainissement de base. Plan national d'action de prévention and de contrôle de l'infection (PCI) au Togo. Lomé; 2017 Togo.

5. Ministre de la santé et de la protection sociale, Direction de l'hygiène et de l'assainissement de base, Division de l'assainissement de base. Evaluation de base de la situation de la prévention et contrôle de l'infection: Rapport Provisoire; 2017.

6. WHO/UNICEF. Water and Sanitation for Health Facility Improvement Tool (WASH FIT). Geneva: World Health Organization; 2017. http://www.who.int/water_sanitation_ health/publications/water-and-sanitation-for-health-facilityimprovement-tool/en/. Accessed September 6, 2018.

7. Admas J, Bartram J, Chartier Y, eds. Essential Environmental Health Standards in Health Care. Geneva: World Health Organization; 2008. http://www.who.int/water_sanitation_ health/publications/ehs_hc/en/. Accessed September 6, 2018.

8. World Health Organization. Guidelines on Core Components of Infection Prevention and Control Programmes at the $\mathrm{Na}$ tional and Acute Health Care Facility Level. Geneva: World Health Organization; 2016. http://www.who.int/gpsc/ipccomponents/en. Accessed September 6, 2018.

9. WHO and IWA. Water Safety Plans Portal. 2018. http:// www.wsportal.org/. Accessed September 6, 2018.

10. Ministère de la Santé et de la Protection Sociale. Presentation et chiffres clés. 2018. http://sante.gouv.tg/fr/content/presentationet-chiffres-cles-0. Accessed September 6, 2018.

11. Hsieh HF, Shannon SE. Three approaches to qualitative content analysis. Qual Health Res 2005;15(9):1277-1288.

12. Neo J, Sagha-Zadeh R, Vielemeyer O, Franklin E. Evidencebased practices to increase hand hygiene compliance in health care facilities: an integrated review. Am J Infect Control 2016;44(6):691-704.

13. Castro-Sánchez E, Holmes AH. Impact of organizations on healthcare-associated infections. J Hosp Infect 2015;89(4): 346-350. 
WEBER ET AL

14. Ojakaa D, Olango S, Jarvis J. Factors affecting motivation and retention of primary health care workers in three disparate regions in Kenya. Hum Resour Health 2014;12:33.

15. Batbaatar E, Dorjdagva J, Luvsannyam A, Savino M, Amenta P. Determinants of patient satisfaction: a systematic review. Perspect Public Health 2017;137(2):89-101.

16. Ider BE, Adams J, Morton A, Whitby M, Clements A. Perceptions of healthcare professionals regarding the main challenges and barriers to effective hospital infection control in Mongolia: a qualitative study. BMC Infect Dis 2012;12: 170.

17. Ministre de la sante publique. Repoblikan’i Madagasikara. Guide technique de mise en œuvre des Formations Sanitaires Amies de WASH.

18. Ministry of Health, Kingdom of Cambodia Nation Religion King. National Guidelines for Water, Sanitation and Hygiene in Health Care Facilities. Department of Hospital Services.
https://www.washinhcf.org/documents/National-Guidelinefor-WASH-in-HCF_FINAL_April-Eng.pdf. Accessed September 6, 2018.

19. Kringos DS, Sunol R, Wagner C, et al. The influence of context on the effectiveness of hospital quality improvement strategies: a review of systematic reviews. BMC Health Serv Res 2015;15:277.

Address correspondence to:
Andrea L. Martinsen, MPH
Emergency Response and Recovery Branch
Division of Global Health Protection
Center for Global Health
Centers for Disease Control and Prevention
Atlanta, GA
Email: xxz1@cdc.gov

